University of Nebraska - Lincoln

DigitalCommons@University of Nebraska - Lincoln

\title{
Effect of Vacuum on the Performance of the Flame Ionization Detector Used for Vacuum-Outlet Gas Chromatography
}

\author{
Ulrich R. Bernier \\ University of Florida, ubernier@gainesville.usda.ufl.edu \\ Christopher L. Bray \\ University of Florida \\ Richard A. Yost \\ University of Florida
}

Follow this and additional works at: https://digitalcommons.unl.edu/usdaarsfacpub

Part of the Agricultural Science Commons

\begin{abstract}
Bernier, Ulrich R.; Bray, Christopher L.; and Yost, Richard A., "Effect of Vacuum on the Performance of the Flame Ionization Detector Used for Vacuum-Outlet Gas Chromatography" (2000). Publications from USDA-ARS / UNL Faculty. 966.

https://digitalcommons.unl.edu/usdaarsfacpub/966
\end{abstract}

This Article is brought to you for free and open access by the U.S. Department of Agriculture: Agricultural Research Service, Lincoln, Nebraska at DigitalCommons@University of Nebraska - Lincoln. It has been accepted for inclusion in Publications from USDA-ARS / UNL Faculty by an authorized administrator of DigitalCommons@University of Nebraska - Lincoln. 


\title{
Effect of Vacuum on the Performance of the Flame Ionization Detector Used for Vacuum-Outlet Gas Chromatography
}

\author{
Ulrich R. Bernier, ${ }^{1}$ Christopher L. Bray, ${ }^{2}$ Richard A. Yost ${ }^{2}$ \\ ${ }^{1}$ United States Department of Agriculture-Agricultural Research Service, 1600 SW 23rd Drive, \\ Gainesville, FL 32608 USA; e-mail: ubernier@gainesville.usda.ufl.edu \\ ${ }^{2}$ Department of Chemistry, University of Florida, Gainesville, FL 32611 USA
}

Received 10 September 1999; revised 11 October 1999; accepted 11 October 1999

\begin{abstract}
Vacuum-outlet operation of short fused-silica open tubular columns for gas chromatography provides benefits to analysis speed by increasing the optimum velocity while minimizing the loss in resolution. Vacuum-outlet operation of a column with a gas chromatographic detector necessitates that the detector also be under vacuum. Simple modifications were made to a gas chromatograph-flame ionization detector (GC-FID) for vacuum-inlet and vacuum-outlet operation. The vacuum-inlet system was operated in the splitless mode to allow for efficient sample loading prior to operation at reduced pressures. The goal of FID operation at 100 torr or less was achieved by using oxygen in place of air and optimizing the gas flows under vacuum to maintain a stable flame at pressures as low as 46 torr. An outlet pressure of 85 torr with optimized gas flows allowed for routine operation of the FID without solvent flame-out. It was discovered that the sensitivity is enhanced compared to atmospheric operation over a range of outlet pressures from approximately 200 to 400 torr; however, operation of the FID at the lowest possible pressures decreases the analytical sensitivity due to both the outlet pressure and the absence of helium makeup gas. ๑ 2000 John Wiley \& Sons, Inc. J Micro Sep 12: 226-235, 2000
\end{abstract}

Key words: vacuum-outlet $G C$; $G C-F I D$; high-speed $G C$

\section{INTRODUCTION}

The benefit of short-column gas chromatography (GC) coupled to mass spectrometry has been described previously [1-9]. Short, wide-bore columns benefit the most from operation of the column outlet at reduced pressure [6,7]. Columns of approximately $10 \mathrm{~m}$ or less provide nearly identical chromatographic separations for outlet pressures of 100 torr or less. The effect of operating these short columns with a reduced outlet pressure results in decreased pressure throughout most of the column leading to an increase in the gas-phase diffusion coefficient. Although the increase in the gas-phase diffusion coefficient does increase the longitudinal diffusion term of the Golay equation, it also decreases the resistance to mass transfer (in the gasphase) term in the same equation. The combined effect of these terms is an increase in the optimum

Correspondence to: Ulrich R. Bernier. linear velocity for minimum plate height, allowing separations to be conducted at almost the same chromatographic efficiency with shorter analysis times $[4,10,11]$. The cost is a slight loss in the number of theoretical plates $[4,9]$.

Due to the high vacuum required in the mass spectrometer ion source, the outlet end of the GC column is under vacuum, shortening migration times of components on the column and providing a form of high-speed gas chromatography. Recently, the most significant improvements in high-speed GC may have been in the area of improved injection systems [10,12-16], reducing sample loading bandwidth; however, incorporating vacuum-outlet operation affords chromatographic advantages to highspeed GC $[11,17]$. In addition to mass spectrometers, other GC detectors such as the thermal conductivity detector (TCD) [18,19], photoionization detector (PID) [19-22], and FID [23] have been used in vacuum-outlet GC. 
Since the flame ionization detector is one of the most common detectors employed for gas chromatographic analyses, work was conducted to adapt the FID for use as a vacuum-outlet detector [23]. Characterization of the effects of vacuum on the FID has not been reported previously; therefore, we have explored the effect on sensitivity resulting from operating the FID under vacuum, including the effect of flame gas flow rates both with and without makeup gas.

\section{EXPERIMENTAL}

A Varian $3400 \mathrm{GC}$ was used in conjunction with an IBM 9000 computer with the Chromatography Applications Program, version 1.4 for data recording. The inlet pressure was controlled by a vacuum pressure regulator, model 182.013 TXM (Negretti \& Zambra, Cape Town, South Africa), which obviated the need for the flow controller used in previous experiments $[9,23]$. The internal gas lines and viton ferrule connections were replaced by $\frac{1}{16}$ in stainless steel tubing and swagelok fittings to prevent any possible leakage of air into the gas lines under vacuum operation.

A diagram of the main components used in this system is shown in Figure 1. To provide for vacuuminlet operation, the split outlet was connected to a 2-stage E2M1.5 rotary vacuum pump (Edwards, Willoughby, $\mathrm{OH}$ ). The pump provided vacuum for both the regulator and the split line. The split valve, which allowed for control of the amount of vacuum in the injection port, was replaced by a Nupro SS2SG needle valve (Jax Valve, Jacksonville, FL) for better control of the vacuum through the split. The injection port pressure was measured by a pressure

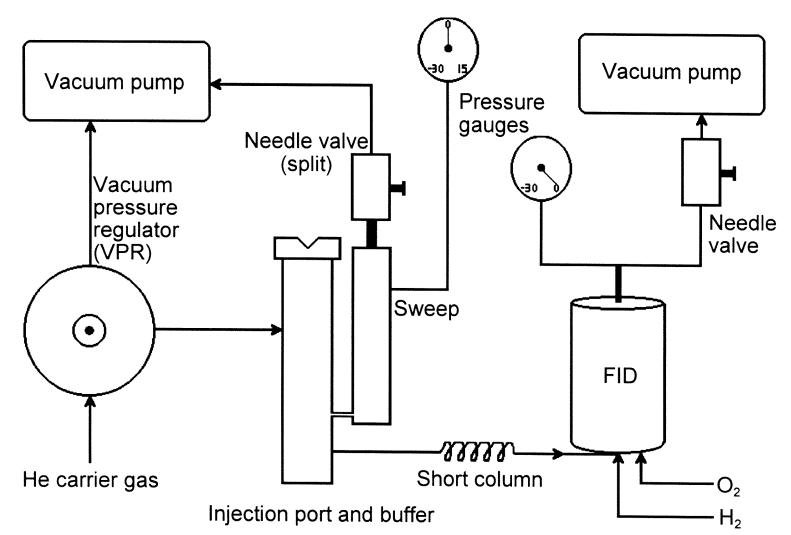

Figure 1. Schematic of the GC-FID system utilized for vacuum-outlet operation of the column and vacuum operation of the injection port and FID. gauge rated from -30 in $\mathrm{Hg}$ to 15 psig (0 to 1520 torr) (Omega Engineering, Stamford, CT) connected to the septum purge line [9].

A stainless steel adapter, consisting of $\frac{1}{4}$ in outer diameter (o.d.) stainless steel tubing welded in the center of a circular stainless steel "block" was designed to seal the top of the FID tower to make the FID vacuum-tight [23]. A $\frac{1}{4}$ in vacuum line was connected to the tower adapter via a three-way swagelok (Jax Valve) tee fitting which allowed for a pressure gauge rated from -30 in $\mathrm{Hg}$ to 0 in $\mathrm{Hg}$ (0-760 torr) (Omega Engineering) to be placed at that location for measurement of the outlet pressure. A Nupro SS-4BMG needle valve (Jax Valve) was connected in the line running to a second 2-stage E2M1.5 rotary vacuum pump (Edwards) to allow alteration of the outlet pressure. The final modification to the FID was switching to oxygen in place of air for the flame gas when operating the detector under vacuum; all gas flows were adjusted on the instrument and measured by a soap bubble flow meter.

A $3.9 \mathrm{~m} \times 0.25 \mathrm{~mm}$ inner diameter (i.d.) $(0.25$ $\mu \mathrm{m}$ film thickness) DB-1 column (J \& W Scientific, Folsom, CA) was used for the studies. The carrier gas was helium. The injection port temperature was set at $150^{\circ} \mathrm{C}$ and the detector at $200^{\circ} \mathrm{C}$. The attenuation on the Varian 3400 was set to 1 for a response range of $10^{-11} \mathrm{~A} / \mathrm{V}$. Splitless injections were made under isothermal conditions at $100^{\circ} \mathrm{C}$; the split solenoid was opened $6 \mathrm{~s}$ after injection to allow the injection port to be operated under vacuum.

The sample analyzed was a $1.0 \mu \mathrm{L}$ injection of an $n$-alkane mixture, comprised of tetradecane, pentadecane, and hexadecane, $30 \mathrm{ng} / \mu \mathrm{L}$ each in isooctane (Varian P/N 82-005-048-07). Average linear velocities were determined by the Poiseuille equation [6] using the inlet and outlet pressure from the gauges. A program written by Mark E. Hail in TurboBASIC running on an IBM PC/386 [9] was employed to calculate the optimum velocities for pentadecane of the three-component mixture. Most of the experiments were conducted by selecting a linear velocity for acquiring the data. After choosing a linear velocity, a PowerBASIC program (Borland International, Scotts Valley, CA) was used to calculate iteratively the inlet pressure required to achieve the specified average linear velocity for a given outlet pressure. The retention factors $\left(k^{\prime}\right)$ were determined by separate experiments with conventional pressure regulation conducted isothermally at $100^{\circ} \mathrm{C}$. For this temperature, the $k^{\prime}$ was 31 for $\mathrm{C}_{15}$. The parameters for experiments were chosen to produce 
a much higher than needed retention factor to guarantee complete resolution of components in the mixture.

\section{RESULTS AND DISCUSSION}

Injection port operation. Most gas chromatographs come equipped with a conventional pressure regulator referenced to $1 \mathrm{~atm}$ pressure to control the inlet. This presented a problem for the efficiency studies once lower outlet pressures were achievable with the FID. Generation of Golay curves with short-columns under vacuum-outlet conditions requires that the inlet pressure be subambient to achieve the optimum linear velocity of carrier gas (as well as lower velocities).

The vacuum pressure regulator (VPR) diagrammed in Figure 1 overcame this problem. It should be noted that the VPR did not solely contribute to the evacuation of the injection port during analysis. The mechanical pump provided vacuum for both the VPR and for the split line, where additional vacuum occurred when the split solenoid was opened for the majority of an analysis. The conventional split valve was replaced by a fine needle valve (as noted in the Experimental section) to provide more precise control of injection port pressures. Additionally, the conventional split valve is designed to function properly only when located directly above the injection port buffer. The buffer opening was designed to fit the split valve when the split control was above the buffer; therefore, this type of split valve was no longer useable. The gauge used to measure injection port pressure was moved from its previously reported location (between the injection buffer and split valve [9]) to the end of the septum purge line to provide more accurate readout of the injection port pressure.

If the split valve is not opened, then the pressure supplied by the VPR is the true injection port pressure throughout the acquisition of the chromatogram. However, for almost all samples analyzed in this work, the solvent front is not readily separated from the earliest eluting mixture components due to the utilization of short columns and vacuum pressures. Therefore, the split valve must be opened to remove any remaining solvent in the injection port. However, enough time must be afforded so that the bands of the mixture components are efficiently loaded onto the column. For the $0.24 \mathrm{~mL}$ volume of the Varian GC injection port, $3 \mathrm{~s}$ were found to be sufficient time to allow sample loading [9]. To insure efficient loading of the sample onto the column, the injection port was set to a higher pressure to quickly deliver the component bands onto the column. This was accomplished by starting the experiment with injection port pressures greater than the desired experimental pressure and then opening the split after two to three times the required sample load time. Once the split solenoid is opened, a new inlet pressure is achieved within seconds and is stable for the duration of the chromatographic run. This produces an insignificant error in the linear velocity calculated by the Poiseuille equation (usually less than $2 \%$ using column parameters reported here).

Column outlet and detector considerations. The outlet pressure was controlled by a fine needle valve along the $\frac{1}{4}$ in o.d. line leading to the vacuum pump (see Figure 1). Due to the large amount of gases (including water vapor) that must be removed from the FID tower, a valve was needed with a high throughput. The outlet pressure fluctuated twice during an analysis. The first occurred upon solvent elution, when the vacuum pressure typically increased by as much as 15 torr; however, the pressure recovered once the split was opened and the solvent in the flame is diminished. The second occurred due to the split valve opening, causing the outlet pressure to decrease due to the drop in inlet pressure. To minimize inaccuracies in pressures resulting from the latter occurrence, inlet and outlet pressures were set at the desired pressures with the solenoid open, prior to resetting the instrument for the subsequent injection.

Conventional FID gas mixture. For atmosphericoutlet operation of the FID, typical flow rates of the hydrogen, air oxidant, and helium makeup gases are 30,300 , and $30 \mathrm{~mL} / \mathrm{min}$, respectively, as prescribed in the Varian 3400 operator's manual [24]. These conditions produce a stable flame for outlet pressures of 335 torr up to and above atmospheric-outlet operation; operation above 760 torr was only performed during early work with the conventional hydrogen, air, and helium composition. Maintaining a stable flame with the conventional gas mixture becomes increasingly difficult with the reduction in outlet pressures below 335 torr. Below this outlet pressure, the detector is susceptible to solvent flame-out; i.e., the flame extinguishes during elution of the abundant solvent. When the $30 \mathrm{~mL} / \mathrm{min}$ of helium makeup gas was eliminated, the flame was stable at outlet pressures down to approximately 230 torr. The need to eliminate the makeup gas is presumably due to the reduced pressure resulting in increased velocities of hydrogen and air, respectively, out of and by the flame tip; the additional flow of helium makeup gas may dilute the fuel and oxidant as well as add to the turbulence near the flame tip. 
Hydrogen-pure oxygen FID gas mixture. Since air is comprised of approximately $20 \%$ oxygen, it is reasonable to assume that an oxygen flow $\frac{1}{5}$ of the normal air flow (i.e., $60 \mathrm{~mL} / \mathrm{min}$ ) would supply enough oxidant to keep the flame stable, while eliminating the noncombustible portion of the air. A mixture of $30 \mathrm{~mL} / \mathrm{min}$ hydrogen and $60 \mathrm{~mL} / \mathrm{min}$ oxygen yielded a stable flame for pressures greater than 130 torr [23]; when helium makeup gas was added, flame stability was achievable down to only 255 torr. The use of pure oxygen and hydrogen is safe provided care is taken not to operate the enclosed FID chamber at pressures above $1 \mathrm{~atm}$ and provided that proper $\mathrm{H}_{2} / \mathrm{O}_{2}$ flow rates are chosen (as described later). Ignition can be performed safely by evacuating the enclosed FID chamber to a pressure below 760 torr before igniting the gas mixture. This routine is performed for all runs with the exception of runs conducted at atmospheric-outlet, where the detector is no longer enclosed, alleviating the explosion hazard.

Without the tower adapter in place (conventional atmospheric-outlet operation), the FID with $\mathrm{O}_{2}$ as the oxidant performs as it would with the normal hydrogen-air flame. Chromatograms run with pure oxygen showed an increase in sensitivity as is discussed below. When the tower adapter is installed on the FID, occasional spikes are present in the chromatograms due to condensed water dripping onto the FID collector. The problem of water condensation is more pronounced with a hydrogenoxygen (compared to hydrogen-air) flame between 600 torr and atmospheric-outlet pressure. The condensation can be minimized by heating the detector to a higher temperature; however, the upper limit for the detector temperature of $250^{\circ} \mathrm{C}$ is dictated by the viton o-ring seal.

Although detector temperatures of up to $250^{\circ} \mathrm{C}$ may be set, poor thermal conduction between the heated detector base-tower and the FID adapter does not allow for the adapter to be heated to $250^{\circ} \mathrm{C}$. It is important to note that heating of the tower assembly is a relatively ineffective remedy to condensation. The easier and better solution is not to allow condensation to occur in the tower-adapter assembly or in the fittings directly above the tower by a simple choice of design. Severe condensation problems arose when the gauge and elbow union connected to the vacuum line were attached directly above the adapter opening. This provided enough distance for water vapor to cool in the unheated $\frac{1}{4}$ in tubing (similar to a reflux condenser) and subsequently drip down into the detector, shorting the signal probe leads. Attaching an elbow union as the first fitting immediately above the adapter remedied this problem; condensation in the horizontal fittings and vacuum line is directed through the vacuum line toward the pump. This configuration allowed for runs to be performed without having to add supplemental heating of the tubing or fittings to prevent condensation.

For operation below 600 torr, water condensation was not found to be a problem inside the detector. It is believed that the uncombusted oxygen, mixed with the flame-produced water vapor, now exit the FID at a high enough velocity that condensation occurs in the vacuum line rather than the tower. The vacuum pump can evacuate the FID chamber to less than 1 torr; however, the lowest pressure at which the flame can be lit (with 30 $\mathrm{mL} / \mathrm{min} \mathrm{H}_{2}$ and $60 \mathrm{~mL} / \mathrm{min} \mathrm{O}_{2}$ ) is 61 torr. The flame at 61 torr is unstable and solvent flame-out occurs upon elution of the solvent off the column. The FID with the aforementioned flow rates of flame gases has been found to give reliable operation with no condensation effects, a stable flame, and no solvent flame-out at outlet pressures of 130 torr or greater.

Optimization of flame gas flows for lowest operable pressure. The goal of achieving an outlet pressure of 100 torr or less could only be met by increasing the flow rate of hydrogen. The lowest ignitible pressure as a function of the hydrogen and oxygen flow rates is plotted as a three-dimensional surface in Figure 2. There is an overall generalization which can be drawn from the figure: higher flow rates of hydrogen yield a more stable flame and lower ignitible pressures provided the oxygen flow rate is near or not much greater than two times the hydrogen flow rate. The lowest ignitible pressure found was 46 torr, corresponding to a stable flame operating pressure of 85 torr or greater. The figure itself is valid only over mixture flows that provide adequate hydrogen and oxygen. The labeled points on the left portion of the graph are indicative of the lowest pressure for a combination of flows. A lit flame is not possible with little or no hydrogen or oxygen flow; this area is located toward the back of the surface plot, having an ignitible pressure of 0 torr. Assignment of any value of "lowest ignitible pressure" to a point at which the flame cannot be lit at any pressure distorts the surface in the area of the plot where no flow of hydrogen or oxygen occurs. Generally, the flame can be lit with hydrogen flows of $20 \mathrm{~mL} / \mathrm{min}$ or greater and oxygen flows of $30 \mathrm{~mL} / \mathrm{min}$ or greater.

A stoichiometric ratio of, for example, 40 $\mathrm{mL} / \mathrm{min} \mathrm{H}_{2}$ and $20 \mathrm{~mL} / \mathrm{min} \mathrm{O}_{2}$, which theoretically should give $100 \%$ combustion of the gases, will 


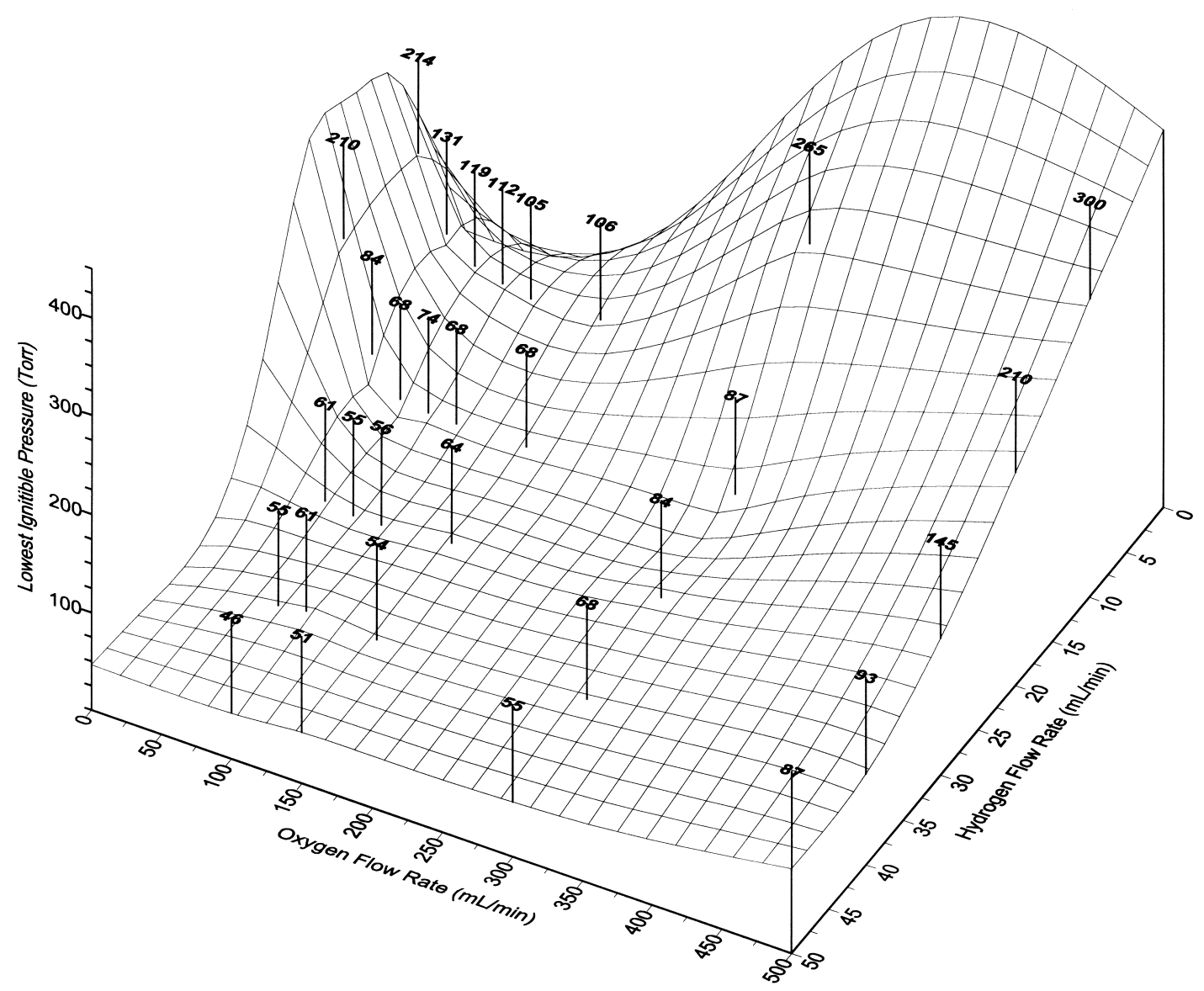

Figure 2. Experimentally determined lowest ignitible pressures for the FID hydrogen-oxygen diffusion flame as a function of chosen hydrogen and oxygen flow rates.

not produce a flame with a stoichiometric burning ratio. This is due to the design of the FID, in which the hydrogen evolves from the flame tip and the oxygen must diffuse from the base and around the tip. Thus, the above example gives a stoichiometric ratio in theory, but experimentally the flame composition would be rich, due to a greater abundance of hydrogen in the flame reaction zone than oxygen. These flow rates are not practical for two reasons. First, any flame composition which is comprised of less oxygen flow than hydrogen flow was found to be unsafe. The presence of an abundance of hydrogen combined with insufficient oxygen can create a danger upon ignition. A specific case was for a 20 $\mathrm{mL} / \mathrm{min}$ flow of both gases that upon ignition created an explosion which was not only audible, but visibly caused movement of the vacuum hose. As the oxygen flow rate was increased to flows greater than that of the hydrogen flow, explosions of this nature were not observed.

The second problem with employing mixtures with less than a 2:1 oxygen to hydrogen ratio of flame gas flows is the formation of soot in the detector. In theory, a 1:1 flow ratio yields a flame which is lean; however, the soot formation (when hydrocarbons were analyzed) indicated the flame still burned rich in hydrogen. This soot formation from incomplete combustion of hydrocarbons is due to a combination of a rich flame, not effectively removing the gases from the detector and not removing the generated heat [25]. Fortunately, ratios of 2:1 or greater oxygen to hydrogen flows do not result in soot formation or condensation problems. Therefore, the flow rates to achieve a lowest operating pressure for routine analyses (85 torr) were chosen to be $50 \mathrm{~mL} / \mathrm{min}_{2}$ and $100 \mathrm{~mL} / \mathrm{min}$ of $\mathrm{O}_{2}$, and this mixture was chosen to examine effects of vacuum on the sensitivity of the FID.

Enhancement of sensitivity due to flame gas composition. The sensitivity or response of the FID is found to vary with both flame gas composition and outlet pressure. The simplest case to analyze is that of a constant outlet pressure, atmospheric-outlet operation in this case. Figure 3 compares the re- 


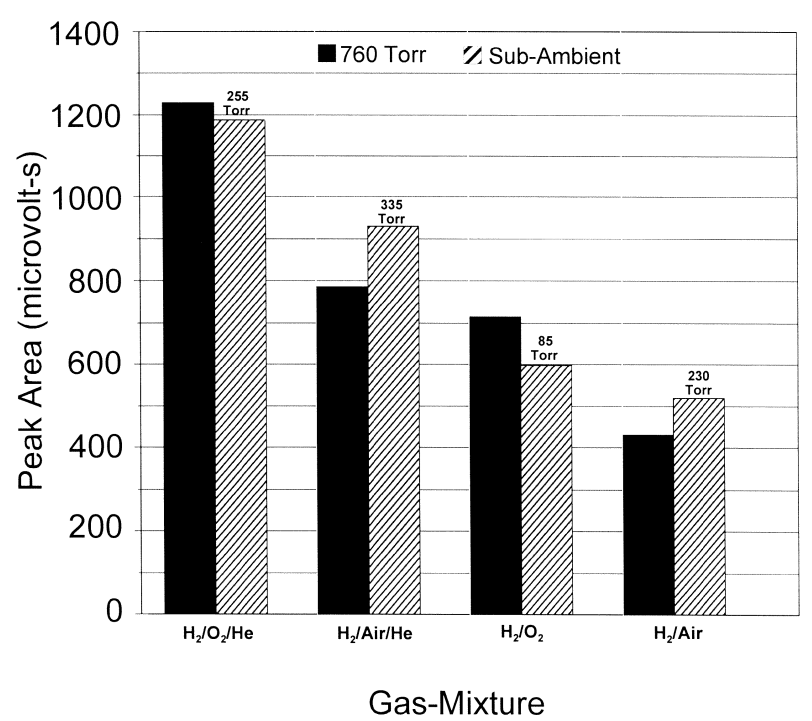

Figure 3. Comparison of peak areas for pentadecane with various flame gas compositions at 760 torr and labeled lowest operable outlet pressures. The flow rates employed are $50 / 100 / 30 \mathrm{~mL} / \mathrm{min} \mathrm{H}_{2} / \mathrm{O}_{2} / \mathrm{He}, 30 /$ $300 / 30 \mathrm{~mL} / \mathrm{min} \mathrm{H}_{2} /$ air $/ \mathrm{Her}, 50 / 100 \mathrm{~mL} / \mathrm{min}_{2}$ $/ \mathrm{O}_{2}$, and $30 / 300 \mathrm{~mL} / \mathrm{min} \mathrm{H}_{2} /$ air.

sponses (in peak area) for pentadecane for different gas mixtures at atmospheric-outlet as well as vacuum-outlet corresponding to the lowest operable pressure for the gas mixture. The gas mixtures are $50 / 100 \mathrm{~mL} / \mathrm{min} \mathrm{H}_{2} / \mathrm{O}_{2}$ and $30 / 300 \mathrm{~mL} / \mathrm{min}$ $\mathrm{H}_{2}$ /air with and without the addition of $30 \mathrm{~mL} / \mathrm{min}$ helium makeup gas. The trends depicted in Figure 3 demonstrate that the addition of helium makeup gas, which is known to improve flame stability, also increases the response of the FID considerably. If vacuum-outlet operation of the GC-FID is of interest, then the enhanced sensitivity achieved by addition of helium makeup gas needs to be weighed against the resulting increase in lowest operable pressure. The substitution of oxygen for air increases the response at atmospheric-outlet pressure as is evidenced by the greater peak areas for the $\mathrm{H}_{2} / \mathrm{O}_{2}$ mixtures both with and without the makeup gas.

The effect of the reduced pressure in the FID with the different flame gas compositions produced somewhat unexpected results when the response at the lowest operable pressures were examined for each composition. The sub-ambient bars in Figure 3 display the responses for the same gas compositions as were previously described for atmospheric-outlet operation. The response order has been reversed, with air providing better sensitivity than oxygen at their respective lowest operating pressures. This was suspected to be an artifact of the different outlet pressures. Addition of helium makeup gas again was found to increase the response, although it is not clear whether it is the presence of the helium or simply the higher outlet pressures that are responsible for this increased response.

Knowledge of the response at the lowest operable pressure for each mixture compared to the responses under the same chromatographic parameters with the FID at atmospheric pressure did not appear to be a gradual decrease in response as outlet pressures were decreased from atmospheric. The peak areas using $\mathrm{H}_{2} /$ air/He at 335 torr were greater than at 760 torr and the peak areas for $\mathrm{H}_{2}$ /air using 230 torr were greater than with 760 torr outlet pressure. This reversal in the magnitude of response was not observed for the $\mathrm{H}_{2} / \mathrm{O}_{2}$ compositions with and without $\mathrm{He}$. To characterize the effect of reduced pressure and further examine if this had a verifiable positive effect, it was necessary to generate response curves for flame gas compositions over a range of outlet pressures.

Effect of outlet pressure on the sensitivity for flame gas compositions. The experiments conducted in the previous section examined the effect of flame gas compositions on sensitivity at the extremes of operation with the column outlet and FID at atmospheric pressure compared to the lowest operable pressure. Only the middle peak, pentadecane, was analyzed, though the last peak, hexadecane, also could have been chosen. The tetradecane peak was not chosen to eliminate potential uncertainty in the peak area measurements since reduced pressure operation resulted in incomplete resolution of this peak from the solvent front.

A comparison of response curves at a constant average linear velocity of $100 \mathrm{~cm} / \mathrm{s}$ for $\mathrm{H}_{2} /$ air at $30 / 300 \mathrm{~mL} / \mathrm{min}$ and $\mathrm{H}_{2} / \mathrm{O}_{2}$ at $50 / 100 \mathrm{~mL} / \mathrm{min}$ over a range of outlet pressures is shown in Figure 4. The top curve (for hydrogen-oxygen) is a spline fit through the average of three replicated measurements at selected discrete outlet pressures. It was found that an operating pressure of approximately 300 torr yielded the maximum response for the FID. This verified the hypothesis that reduced pressures did result in an increased response and that a maximum was present as the pressure was reduced further. The experiment leading to the generation of this curve was repeated in triplicate and generated similar curves each time, although offset in each case with respect to peak area. 


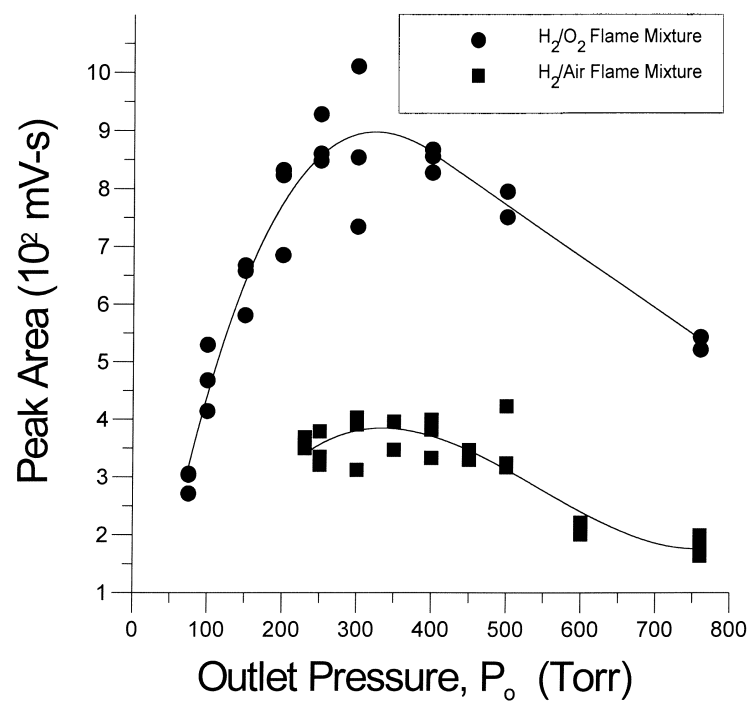

Figure 4. Comparison of peak areas for pentadecane with $50 / 100 \mathrm{~mL} / \mathrm{min} \mathrm{H}_{2} / \mathrm{O}_{2}$ and $30 / 300 \mathrm{~mL} / \mathrm{min}$ $\mathrm{H}_{2}$ /air flame gas mixtures as a function of the outlet pressure. The inlet pressure was adjusted to produce a constant average linear velocity of $100 \mathrm{~cm} / \mathrm{s}$.

The increased response of the flame using oxygen rather than air is evident at any outlet pressure. The only point at which the hydrogen-oxygen produced a lower response than the hydrogen-air flame (at any pressure) was at an outlet pressure of 85 torr. This accounts for the response reversal found previously. The hydrogen-air curve contains no experimental points below the minimum operable outlet pressure of 230 torr. If the flame were operable below this pressure, then it is inferred from the shape of the response curves that the hydrogen-air response would continue to be less than that of hydrogen-oxygen at all similar outlet pressures of comparison.

The shapes of the response curves for both gas compositions are similar. Although the absolute increase in peak area for the hydrogen-oxygen flame is greater, the maximum response for both curves is approximately 1.5 -fold higher than the response at atmospheric outlet pressure, and occurs at approximately the same outlet pressure (325 torr). This suggests that vacuum enhances the FID sensitivity independent of the choice of flame gas composition.

One possible explanation for the shape of the response curves in Figure 4 is pressure-dependent loss of sample in the injection port once the split solenoid is opened. Sample loading onto the column was addressed previously, and should not give rise to experimental problems; nevertheless, the response curve shapes at the lower and higher outlet pres- sures suggest the possibility of sample loss. The data in Figure 4 were generated under conditions of constant average linear velocity, which required varying both the column outlet pressure and the injection port pressure. The injection port pressure was changed by adjusting the vacuum pressure regulator and leaving the split needle valve at a constant setting. It is conceivable that at higher injection port pressures, the sample might have been loaded onto the column more rapidly than at lower outlet pressures. Any sample not loaded onto the column would have exited more rapidly through the split due to the larger split ratio arising from the large pressure difference across the split needle valve. Thus at lower outlet pressures, if the split valve was opened (at $6 \mathrm{~s}$ ) before the sample is completely loaded onto the column, a loss of sample may occur.

Therefore, the above experiment was repeated at a constant inlet pressure, rather than at constant average linear velocity; this maintains essentially constant injection port conditions and eliminates any pressure change effects that may contribute to sample loss. The retention times and peak heights, however, will now vary due to the changes in the average linear velocity of the helium carrier gas. Fortunately, the FID is tolerant to changes in the carrier velocity, and therefore the response curve (generated from peak areas) should not be affected greatly. Since the carrier gas is helium, and helium makeup gas was found to enhance sensitivity, it might be expected that the helium carrier gas will improve sensitivity as greater velocities are employed. The hypothesis was that if the shapes of the curves are similar for constant linear velocity and constant inlet pressure, regardless of the offset in detector response, then these curves are valid and the shape of the curve cannot be attributed to sample loss. Figure 5 demonstrates that the shapes of the response curves are indeed similar. An offset in corresponding values of peak areas is evident, particularly at higher outlet pressure.

Of great interest is the variation in the offset over the outlet pressure range. The average linear velocity for the constant velocity curve is $100 \mathrm{~cm} / \mathrm{s}$; the constant inlet pressure experiment was conducted with average linear velocities of helium carrier gas ranging from $218 \mathrm{~cm} / \mathrm{s}$, at the 85 torr outlet pressure, to $70 \mathrm{~cm} / \mathrm{s}$ at atmospheric-outlet. The increased flow of helium into the FID at low outlet pressures is thought to be analogous to the addition of helium makeup gas. As was observed in Figure 3, addition of helium makeup gas improved response. This increase in helium may be the cause of the shift in the optimum to lower pressure for the constant inlet pressure curve. The curve acquired with con- 


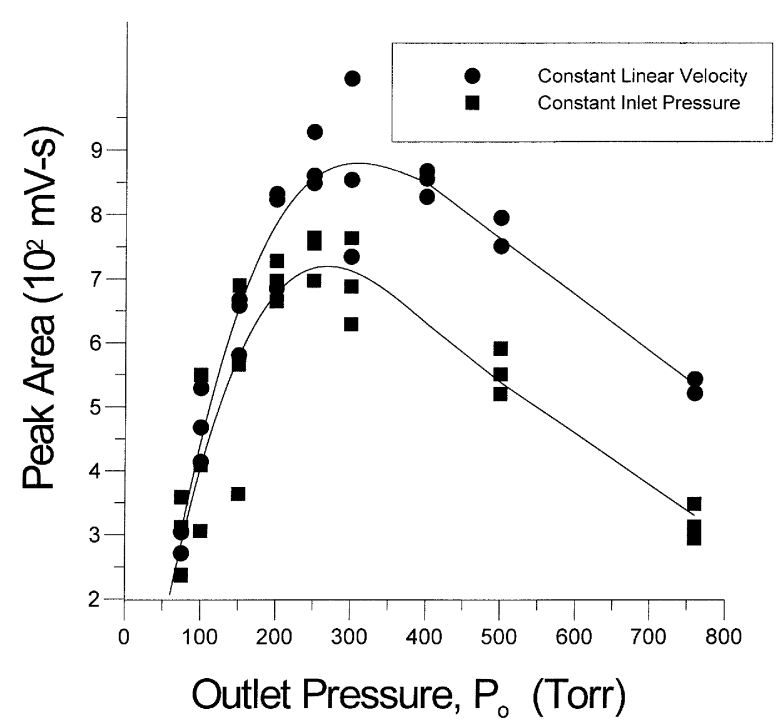

Figure 5. Comparison of peak areas for pentadecane with $50 / 100 \mathrm{~mL} / \mathrm{min} \mathrm{H}_{2} / \mathrm{O}_{2}$ using helium carrier gas at a constant linear velocity of $100 \mathrm{~cm} / \mathrm{s}$ (Figure 4) compared to the same mixture run with a constant inlet pressure of 1000 torr, generating average velocities of $218 \mathrm{~cm} / \mathrm{s}$ down to $70 \mathrm{~cm} / \mathrm{s}$.

stant average linear velocity does not display such an effect because the linear velocity (and hence the flow rate) of helium is held constant.

The maximum response found in the 325 torr outlet pressure region may have a number of possible causes. The most likely is that the $50 / 100$ $\mathrm{mL} / \mathrm{min} \mathrm{H}_{2} / \mathrm{O}_{2}$ flow rates do not produce a flame with optimum ionization efficiency at atmosphericoutlet. As the gases are subjected to lower pressures in the FID, their velocities increase, but they may not increase in direct proportion to each other, resulting in the peak area profiles found in Figures 4 and 5. These profiles are similar to sensitivity profiles found by optimizing hydrogen and air flows for normal atmospheric operation of the FID [23].

Another possibility is that under reduced pressure there is a greater mobility of ions to the collector due to less interference from reduced gases, thereby explaining the increase in peak area as the outlet pressure is dropped from 760 torr to approximately 325 torr. As outlet pressures are reduced even further, the migration times for the ions to the collector may not be short enough to compensate for the increased velocity of the gases (and hence the ions) out of the flame tip past the collector, and out of the FID.

A physical explanation might also be possible. Elution of components into the flame generates a hydrocarbon flame which can be a few centimeters

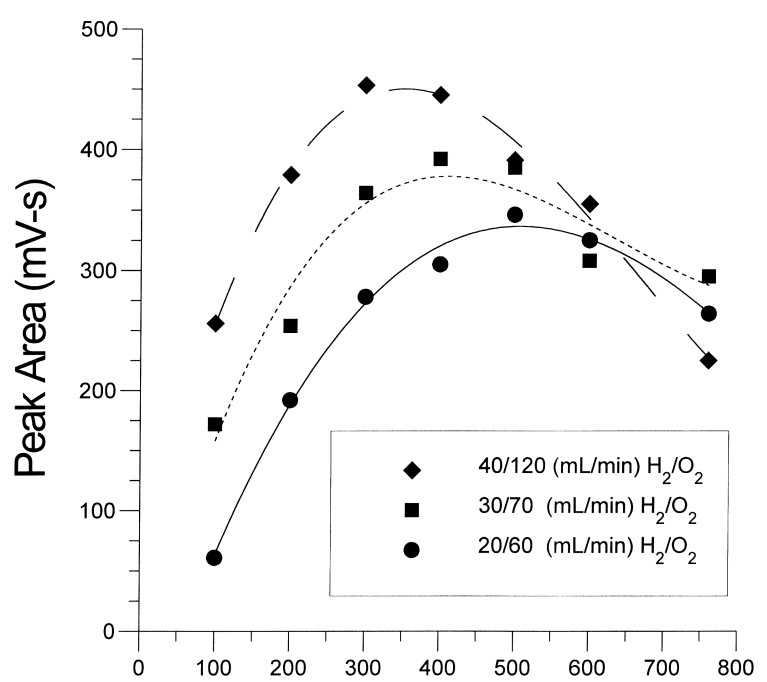

\section{Outlet Pressure (Torr)}

Figure 6. Comparison of peak areas for pentadecane with flow rates of $40 / 120,30 / 70$, and $20 / 60 \mathrm{~mL} /$ min $\mathrm{H}_{2} / \mathrm{O}_{2}$ using helium carrier gas at a constant average linear velocity of $100 \mathrm{~cm} / \mathrm{s}$.

high $[25,26]$. At atmospheric operation, the flame may be lower than the collector and the ions produced are moved up into the collector region by the hot uncombusted gases. As the pressure is reduced, the flame height may increase such that the reaction zone is now directly surrounded by the collector. This would provide the shortest migration path of ions to the collector. However, as outlet pressures are reduced even further, the reaction zone may now rise above the collector. This could explain the diminishing response at low outlet pressures in Figures 4 and 5. If the reaction zone is above the collector then the ions must migrate against the flow of hot gases to reach the collector.

One further study was conducted to examine response curves for various flow rates of hydrogen and oxygen at constant linear velocity to determine if 325 torr was also the optimum pressure with respect to sensitivity for other gas flow rates. Figure 6 compares three different compositions. A trend is evident where the maximum overall sensitivity increases as the hydrogen flow rate is increased. Additionally, the maximum sensitivity occurs at lower outlet pressures as the hydrogen flow rate is increased.

This effect is mirrored by changes in oxygen flow rate, as can be seen in Figure 7. This response surface was generated by examining hydrogen flows of $10-40 \mathrm{~mL} / \mathrm{min}$, coupled with oxygen flows of 


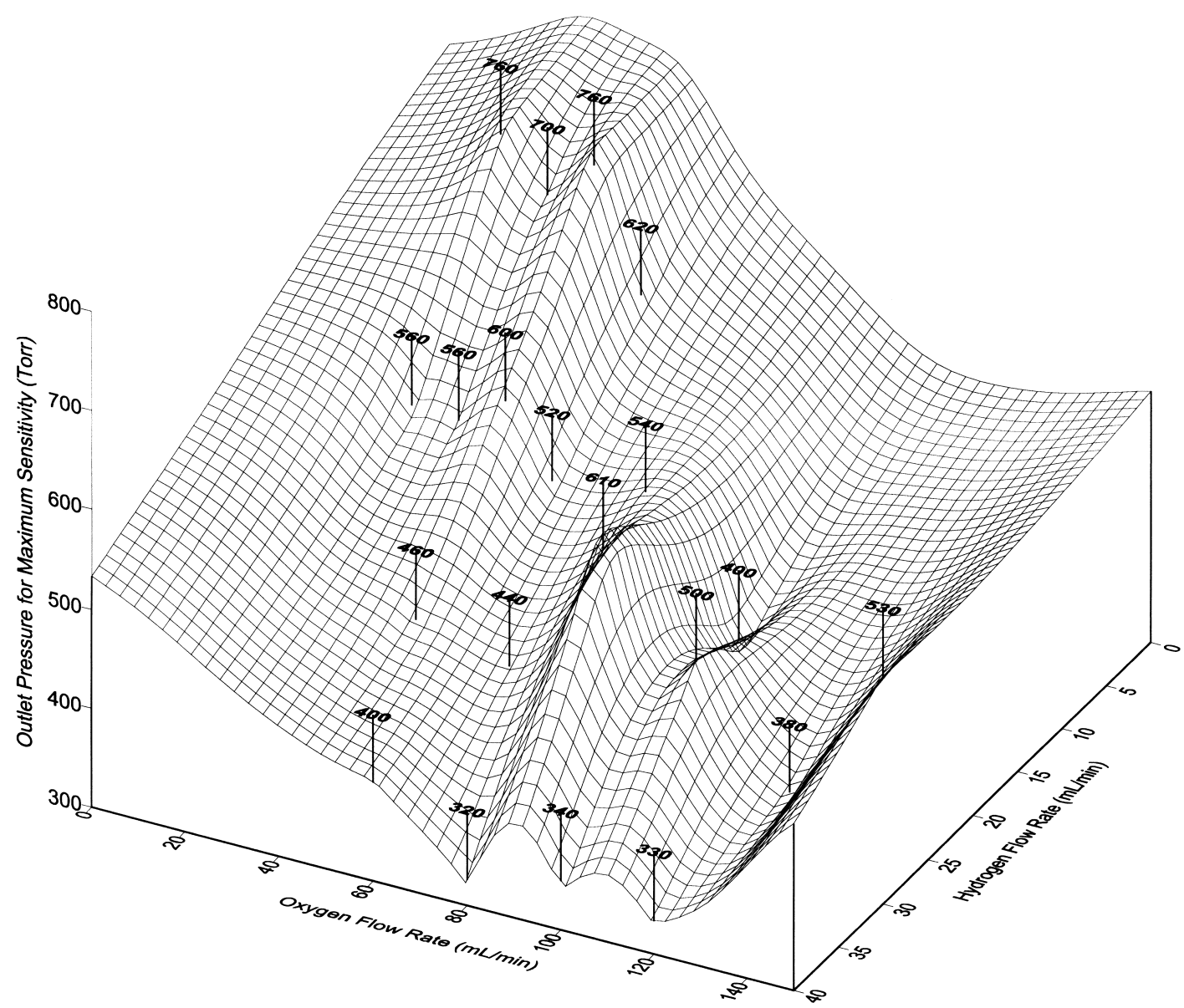

Figure 7. Experimentally determined outlet pressure for maximum sensitivity for various flow rates of hydrogen $(10-40 \mathrm{~mL} / \mathrm{min})$ and oxygen $(20-150 \mathrm{~mL} / \mathrm{min})$.

$20-150 \mathrm{~mL} / \mathrm{min}$, using a minimum $1: 1$ ratio of hydrogen to oxygen. The figure does indicate that an increase in optimum pressure occurs as the oxygen to hydrogen ratio is increased above $3: 1$. Over the range of flow rates examined, the lowest optimum pressure for maximum sensitivity was 320 torr. It is not expected that this will decrease to a significantly lower value for higher flow rates of hydrogen and oxygen because of the high rate of flow from the combined gases into the detector. The surface does fluctuate slightly in the $30 \mathrm{~mL} \mathrm{H}_{2} / 80 \mathrm{~mL} \mathrm{O}_{2}$ and 30 $\mathrm{mL} \mathrm{H}_{2} / 100 \mathrm{~mL} \mathrm{O}_{2}$ regions. These are believed to be experimental imprecision which remains after smoothing the surface.

This work demonstrates that a flame ionization detector can be operated at a pressure of 85 torr, provided gas flows are optimized. Thus, it is possible to use the FID in vacuum-outlet high-speed GC at pressures which impart almost the full benefit of vacuum operation used with short column GC-MS. In addition, the sensitivity of the FID was found to be greater under reduced pressure than corresponding ambient operation.

\section{ACKNOWLEDGMENT}

The authors thank Dr. Jodie Johnson, Professor Richard Sacks, and Dr. Steven Valles for reviewing an earlier version of this manuscript.

\section{REFERENCES}

1. Sellier, N.; Guiochon, G. J Chromatogr Sci 1970, 8, 147-150.

2. Hatch, F. W.; Parrish, M. E. Anal Chem 1978, 50, 1164-1168.

3. Vangaever, F.; Sandra, P.; Verzele, M. Chromatographia 1979, 12, 153-154.

4. Cramers, C. A.; Scherpenzeel, G. J.; LeClercq, P. A. J Chromatogr 1981, 203, 207-216.

5. LeClercq, P. A.; Scherpenzeel, G. J.; Vermeer, E. A. A.; Cramers, C. A. J Chromatogr 1982, 241, 61-71.

6. Trehy, M. L.; Yost, R. A.; Dorsey, J. G. Anal Chem, 1985, 58, 14-19.

7. LeClercq, P. A.; Cramers, C. A. J High Resolut Chromatogr Chromatogr Commun 1987, 10, 269-272. 
8. Hyver, K. J.; Phillips, R. J. J Chromatogr 1987, 399, 33-46.

9. Hail, M. E.; Yost, R. A. Anal Chem 1989, 61, 2402-2410.

10. Nowak, M.; Gorsuch, A.; Smith, H.; Sacks, R. Anal Chem 1998, 70, 2481-2486.

11. Cramers, C. A.; LeClercq, P. A. CRC Crit Rev Anal Chem 1988, 20, 117-147.

12. van Es, A.; Jansen, J.; Bally, R.; Cramers, C.; Rijks, J. J High Resolut Chromatogr Chromatogr Commun 1987, 10, 273-279.

13. Lanning, L. A.; Sacks, R. D.; Mouradian, R. F.; Levine, S. P.; Foulke, J. A. Anal Chem 1988, 60, 1994-1996.

14. Liu, Z.; Zhang, M.; Phillips, J. B. J Chromatogr Sci 1990, 28, 567-571.

15. Klemp, M.; Sacks, R. J Chromatogr Sci 1991, 29, 243-247.

16. Leonard, C.; Liu, H.-F.; Brewer, S.; Sacks, R. Anal Chem 1998, 70, 3498-3504.
17. Giddings, J. C. Anal Chem 1962, 34, 314-319.

18. Palamand, S. R.; Thurow, D. O. J Chromatogr 1969, 40, 152-155.

19. Noij, T.; Rijks, J. A.; van Es, A. J.; Cramers, C. A. J High Resolut Chromatogr Chromatogr Commun 1988, 11, 862-869.

20. van Es, A.; Cramers, C.; Rijks, J. J High Resolut Chromatogr Chromatogr Commun 1989, 12, 303.

21. Puig, L.; Sacks, R. D. J Chromatogr Sci 1991, 29, $158-164$.

22. Smith, H.; Zellers, E. T.; Sacks, R. D. Anal Chem 1999, 71, 1610-1616.

23. Bernier, U. R.; Yost, R. A. J Chromatogr Sci 1993, 31, 358-362.

24. Varian Model 3300/3400 Operator's Manual; Varian Associates Inc.: Walnut Creek, CA 94598, 1989.

25. Modern Practice of Gas Chromatography; Grob, R. L., Ed.; John Wiley \& Sons: New York, 1985.

26. Bocek, P.; Janak, J. J Chromatogr Rev 1971, 15, 111-150. 